\title{
O SISTEMA PRISIONAL DO BRASIL À LUZ DOS PRINCÍPIOS DO MÍNIMO EXISTENCIAL E DA RESERVA DO POSSÍVEL
}

\section{THE BRAZILIAN PRISON SYSTEM IN THE LIGHT OF THE PRINCIPLES OF MINIMUM EXISTENTIAL AND RESERVATION OF THE POSSIBLE}

\author{
Isabela Duran Cavalcante LACERDA ${ }^{1}$, Danilo Henrique NUNES ${ }^{2}$ \\ ${ }^{1}$ Centro Universitário da Fundação Educacional de Barretos - Unifeb. Av. Professor Roberto Frade \\ Monte 389, Aeroporto, CEP 14283-078, Barretos-SP. \\ ${ }^{2}$ Advogado e professor do Centro Universitário da Fundação Educacional de Barretos - Unifeb. Av. Professor \\ Roberto Frade Monte 389, Aeroporto, CEP 14283-078, Barretos-SP.
}

\section{RESUMO}

O presente trabalho visa discorrer sobre a atual situação do sistema prisional brasileiro e os vários atentados à Constituição Federal no tocante aos direitos humanos e fundamentais, além da falta de ação e a omissão dos Poderes Públicos. A CF/88 possibilita a todos os indivíduos, não excluindo os presos, direitos fundamentais; em auxílio a ela, temos o princípio do mínimo existencial - que visa garantir condições mínimas de existência humana digna. Todavia ambos são feridos quando paramos para analisar que os detentos vivem em condições desumanas, com péssimas condições higiênicas, má alimentação, superlotação de presídios e uma saúde degradante. $\mathrm{O}$ art. $5^{\circ}$, XLIX da $\mathrm{CF} / 88$ garante aos presos o direito à integridade física e moral, com isso, o fato de ser restrito do seu direito de liberdade, não implica sobre o direito à sua dignidade. A instituição prisão tem o intuito de promover a ressocialização e reinserção dos detentos, porém, nesta instituição, acaba ocorrendo à violação dos direitos básicos da pessoa, o indivíduo é preso para lhe ser retirado o direito de ir e vir, e, apesar de todos os outros direitos serem garantidos pela lei, acabam sendo feridos neste meio. Outra característica do princípio do mínimo existencial refere-se aos direitos positivos, pois exige que o Estado ofereça condições para a aplicabilidade dos direitos fundamentais. Porém há também o princípio da reserva do possível que afirma que deve ser feita uma análise da reserva orçamentária disponível, em que o Estado só realiza o que for preciso se estiver dentro de sua capacidade econômica. O método aplicado na pesquisa foi o hipotético - dedutivo, pois a partir da análise doutrinária e de referenciais teóricos, além de análise de casos concretos. Por fim, diante dessa divergência de princípios, há de ser feito um juízo de ponderação, em que se deve equilibrar o mínimo existencial e a reserva do possível: o Estado há de preservar a dignidade da pessoa humana, respeitando também os seus limites financeiros.

Palavras-chave: Direitos Fundamentais; Princípios; Dignidade Humana; Privatização.

\begin{abstract}
This paper aims to discuss the current situation of the Brazilian prison system and the various attacks on the Federal Constitution regarding human and fundamental rights, as well as the lack of action and omission of the Public Powers. The $\mathrm{CF} / 88$ provides to all individuals, including prisoners, fundamental rights, along
\end{abstract}

Autor para correspondência: Isabela Duran Cavalcante Lacerda - Centro Universitário da Fundação Educacional de Barretos (UNIFEB), Av. Professor Roberto Frade Monte, 389, Aeroporto - CEP: 14283-078 - Barretos - SP, Brasil - E-mail: isabeladurancl@hotmail.com

Recebido em: 07 de julho de 2017

Aceito para publicação em: 09 de outubro de 2017 
with the minimum existential principle - which aims to guarantee minimum conditions of human dignity. However, both are injured when we analyze the detainees inhuman living conditions, with poor hygienic conditions, poor food, overcrowding of prisons and degrading health. The Art. 5, XLIX of CF/88 ensures the prisoners with the right to physical and moral integrity. The fact that they are restricted from their right to freedom does not imply the right to their dignity. The prison institution aims to promote resocialization and reintegration of detainees; however, there is a violation of the basic rights. The individual is arrested to be denied the right to come and go, but all other rights that are guaranteed by law, end up being injured in this environment. Another characteristic of the principle minimum existential is positive rights, since the State is required to provide conditions for the applicability of fundamental rights. In addition, the principle of reservation of the possible states that an analysis of the available budget reserve should be made, where the State only accomplishes what is necessary if it is within its budget. Finally, in the face of this divergence of principles, a weighty judgment must be made, in which the minimum existential and the reservation of the possible must be balanced: the State must preserve the dignity of the human person, while respecting its financial limits

Keywords: Fundamental rights; Principles; Human dignity; Privatization.

\section{INTRODUÇÃO}

Nos primórdios, os direitos e garantias fundamentais surgiram como uma necessidade de se limitar e controlar as atuações estatais e das autoridades constituídas por ele. Originou-se como uma proteção à liberdade do indivíduo em face da atuação abusiva do Estado, exigindo-se deste, primeiramente, uma abstenção, um não fazer do Estado em consideração à liberdade individual, culminando com os chamados direitos negativos, liberdades negativas (DIÓGENES JÚNIOR, 2016)

Há uma verdadeira balbúrdia terminológica que assola a doutrina. Podemos registrar, por exemplo, autores que usam nomes tão díspares quanto "direitos humanos", "direitos humanos fundamentais", "liberdades públicas", "direitos dos cidadãos", "direitos da pessoa humana”, "direitos do Homem", etc. É preciso, porém, sedimentar uma terminologia adequada, pois se trata de uma questão essencial (TAVARES, 2010).

Os direitos fundamentais podem ser conceituados como a categoria jurídica instituída com a finalidade de proteger a dignidade humana em todas as dimensões. Por isso, tal qual o ser humano, tem natureza polifacética, buscando resguardar o homem na sua liberdade (direitos individuais), nas suas necessidades (direitos sociais, econômicos e culturais) e na sua preservação (direitos relacionados à fraternidade e à solidariedade) (ARAUJO; NUNES JÚNIOR, 2005, p. 109-110).

Previstos no artigo $5^{\circ}$ da Constituição Federal, os direitos fundamentais, sendo estes invioláveis, garantem aos indivíduos uma proteção perante o poder estatal.
Como forma de auxiliar a Constituição, com o intuito de garantir a efetivação da aplicabilidade dos direitos fundamentais, tem-se o princípio do mínimo existencial que é visto por Luís Fernando Barroso como o

conjunto de prestações materiais que asseguram a cada indivíduo uma vida com dignidade, que necessariamente só poderá ser uma vida saudável, que corresponda a padrões qualitativos mínimos (BARROSO apud SARLET, 2003).

O princípio do mínimo existencial volta-se também para o sentido de garantir a dignidade da pessoa humana, Tugendhat (2000) diz que a dignidade aponta para certo nível de satisfação das necessidades, uma vez que um ser humano precisa do mínimo de existência para que ele possa gozar os seus direitos e para que leve, neste sentido, uma existência humanamente digna. Dentro deste contexto, o homem e o respeito à sua dignidade tornaram-se o foco de todo o sistema jurídico, pois

a dignidade da pessoa humana é um superprincípio do sistema jurídico [...], valor supremo consagrado no texto constitucional e que informa todo o sistema jurídico (SIQUEIRA JUNIOR, 2009, p. 253).

Destaque-se ainda, a importante alusão feita em relação às pessoas que se encontram privadas de sua liberdade, reafirmando o respeito que se deve ter por elas, pois o fato de estarem presas não interfere em nada em sua dignidade, pois ela - a dignidade - é inerente ao ser humano. Isso afasta completamente a possibilidade da aplicação de penas ou tratamentos cruéis, desumanos ou degradantes (BERTONCINI; MARCONDES, 2016). 
A realidade vivida dentro do sistema penitenciário brasileiro é assustadora, os detentos vivem em condições desumanas, como animais, em celas com péssima higiene, com mais detentos do que seria permitido, uma saúde precária e péssima alimentação, o que fere diretamente o princípio do mínimo existencial e a dignidade humana.

Em contestação ao princípio do mínimo existencial, existe o princípio da reserva do possível, que busca proteger financeira e economicamente 0 Estado, buscando avaliar o seu orçamento financeiro antes de realizar qualquer mudança necessária.

\section{MATERIAIS E MÉTODOS}

O presente trabalho é uma pesquisa realizada na área de Direito Constitucional, Direitos Humanos e Direito Penal, analisa a situação do sistema penitenciário brasileiro, relacionando-a com os princípios do mínimo existencial e da reserva do possível, a partir de conceitos doutrinários.

É feita uma abordagem ao artigo $5^{\circ}, \mathrm{CF} / 88$ e seus incisos, ao princípio do mínimo existencial como garantia dos Direitos Fundamentais e ao da reserva do possível como meio de defesa orçamentária do Estado, buscando uma conciliação entre os dois (CONSTITUIÇÃO FEREDAL, BRASIL, 1988, art. $5^{\circ}$ ). Compreender e contextualizar os princípios do mínimo existencial e da reserva do possível e destacar entendimentos doutrinários sobre eles. Bem como, é realizada uma análise aos princípios do mínimo existencial e da reserva do possível, com o intuito de encontrar um equilíbrio entre os poderes, para que os dois princípios sejam respeitados, assim como a dignidade da pessoa humana.

O presente estudo é feito por meio dos métodos dedutivo, indutivo e comparativo.

O método Dedutivo vem de ideias gerais e, a partir disso, são vistas como uma série de deduções que logo se empregam com os dados concretos da realidade.

O método Indutivo é o raciocínio que parte de uma análise de uma quantidade suficiente de casos particulares para concluir uma realidade geral, a ciência começa com a observação. Neste método, considera-se a situação de vários sistemas prisionais para chegar-se a uma ideia geral sobre eles.

O método comparativo efetua comparações com o objetivo de certificar as semelhanças dos grupos existentes, daqueles que existiram no passado, relacionando com os do presente em estágios diversos de desenvolvimento.

\section{RESULTADOS E DISCUSSÃO}

A ideia moderna de humanidade, inclusive, como conclui o filósofo Francês Luc Ferry, implica a consideração da liberdade como característica inerente ao indivíduo, tendo ela e a dignidade uma origem de reconhecimento concomitante na história do homem (FERRY, 2007).

Os estabelecimentos da atualidade não passam de monumentos de estupidez. Para reajustar homens à vida social, invertem os processos lógicos de socialização; impõem silêncio ao único animal que fala; obrigam a regras que eliminam qualquer esforço de reconstrução moral para a vida livre do amanhã, induzem a um passivismo hipócrita pelo medo do castigo disciplinar, ao invés de remodelar caracteres ao influxo de nobres e elevados motivos; aviltam e desfibram, ao invés de incutirem o espírito de hombridade, o sentimento de amor-próprio; pretendem, paradoxalmente, preparar para a liberdade mediante um sistema de cativeiro (MUAKAD, 1998).

Beccaria considerava a prisão como: "horrível mansão do desespero e da fome" (BECCARIA, 1993, p. 35). De um modo geral, as deficiências prisionais apresentam muito mais características semelhantes aos tempos dos suplícios. É comum e corriqueiro se constatar, nos presídios, maus tratos verbais ou de fato, superpopulação carcerária, o que também leva a uma drástica redução de desfrute de outras atividades que deve proporcionar o centro penal; falta de higiene; condições deficientes de trabalho, o que pode significar uma inaceitável exploração dos reclusos ou ócio completo; deficiências do serviço médico, que pode chegar em muitos casos, a sua absoluta inexistência; regime alimentar deficiente; elevado índice de consumo de drogas, muitas vezes originado pela venalidade e corrupção de alguns funcionários penitenciários que permitem e até realizam o tráfico; reiterados abusos sexuais; ambiente propício à violência, em que impera a utilização de meios brutais e sempre se impõe o mais forte (BITENCOURT, 1993).

Para garantir a ressocialização e reintegração dos detentos, além de melhorar as suas instalações, sua saúde, higiene e alimentação, muitas mudanças devem ser feitas dentro do sistema prisional. Há quem diga que educar dentro das prisões é a 
solução e há quem afirme que privatizar seria o único meio.

Um dos objetivos da política criminal integrada na política social será tentar a transformação da instituição penitenciária em escola de alfabetização e profissionalização do preso, para inseri-lo no processo de desenvolvimento da Nação, a serviço do bem comum. A administração penitenciária tem o dever de ofertar ao preso todas as possibilidades de instrução escolar e formação profissional (ALBERGARIA, 1993).

A ideia contemporânea de privatização dos presídios surgiu em meio a um sistema penitenciário falido, no qual a pena de prisão, forma de sanção ainda aplicada na grande maioria dos crimes, encontra-se em franco declínio, marcada por uma excessiva crueldade e responsável pelo completo perdimento da pessoa do preso para o retorno da vida em sociedade (CORDEIRO, 2006)

A Parceria Público-Privada veda expressamente a superlotação. Assim, tem-se uma garantia de que os inúmeros problemas enfrentados pelos presos em processo de ressocialização sejam reduzidos, como também haverá a redução dos gastos estatais de forma indireta. Consequentemente, reduzir-se-ão as rebeliões, que é um dos pontos em que há mais gastos, pelo fato de ocorrer a depredação do patrimônio estatal (OLIVEIRA, 2008).

As modificações introduzidas no sistema penitenciário são insuficientes para atender a sua verdadeira finalidade, qual seja recuperar os delinquentes para que, ao retornarem à sociedade, possam tornar-se cidadãos úteis e não um peso para ela, que talvez tenha sido a própria causadora de sua deficiência (MUAKAD, 1998).

Muitas mudanças devem ser feitas dentro do sistema prisional, no entanto o princípio da reserva do possível age como um limite para os gastos do Estado e, antes que qualquer modificação possa ser feita, terá de haver uma análise orçamentária estatal, porém, como o princípio do mínimo existencial no seu aspecto positivo exige do Estado condições para a aplicabilidade dos Direitos Fundamentais, é necessário um equilíbrio entre os dois princípios.

Sustenta-se, por exemplo, inclusive entre nós, que a efetivação destes direitos fundamentais encontra-se na dependência da efetiva disponibilidade de recursos por parte do Estado, que, além disso, deve dispor do poder jurídico, isto é, da capacidade jurídica de dispor. Ressalta-se, outrossim, que constitui tarefa cometida precipuamente ao legislador ordinário a de decidir sobre a aplicação e destinação de recursos públicos, inclusive no que tange às prioridades na esfera das políticas públicas, com reflexos diretos na questão orçamentária, razão pela qual também se alega tratar-se de um problema eminentemente competencial. Para os que defendem esse ponto de vista, a outorga ao Poder Judiciário da função de concretizar os direitos sociais, mesmo à revelia do legislador, implicaria afronta ao princípio da separação dos poderes e, por conseguinte, ao postulado do Estado de Direito (SARLET, 2003)

É diante de situações concretas, sempre no contexto de uma relação meio-fim, que devem ser aferidos os critérios de razoabilidade e proporcionalidade, podendo o Poder Judiciário, desde que provocado, apreciar se as restrições impostas pela Administração Pública são adequadas, necessárias e justificadas pelo interesse público; se o ato implicar limitações inadequadas, desnecessárias ou desproporcionais (além da medida) deverá ser anulado (ALEXANDRINO; PAULO, 2010).

\section{CONCLUSÃO}

O Brasil é, sem sombra de dúvida, sujeito ativo de muitas violações de Direitos Humanos, ou seja, é autor de muitos ilícitos internacionais humanitários ou 'jus humanitários'. Seja em razão de violência dos seus próprios agentes, seja por força de sua omissão, certo é que o Estado brasileiro já começou a responder por esses ilícitos (GOMES; MAZZUOLI, 2016).

O preso conserva todos os direitos não atingidos pela perda da liberdade, impondo-se a todas as autoridades o respeito à sua integridade física e moral (CÓDIGO PENAL, BRASIL, 2016, art.38). Talvez esse seja um dos artigos mais desrespeitados de nossa legislação penal. A toda hora, testemunhamos, pelos meios de comunicação, a humilhação e o sofrimento daqueles que por algum motivo se encontram em nosso sistema carcerário. Não somente os presos provisórios, que ainda aguardam julgamento nas cadeias públicas, como também aqueles que já foram condenados e cumprem pena nas penitenciárias do Estado. $\mathrm{Na}$ verdade, temos problemas em toda a federação. Motins, rebeliões, mortes, tráfico de entorpecentes e de armas ocorrem com frequência em nosso sistema carcerário. A pena é um mal necessário. No entanto, o Estado, quando faz valer o seu ius puniendi, deve preservar as condições mínimas 
de dignidade da pessoa humana. O erro cometido pelo cidadão ao praticar um delito não permite que o Estado cometa outro, muito mais grave, de tratá-lo como um animal. Se uma das funções da pena é a ressocialização do condenado, certamente num regime cruel e desumano isso não acontecerá. As leis surgem e desaparecem com a mesma facilidade. Direitos são outorgados, mas não são cumpridos. O Estado faz de conta que cumpre a lei, mas o preso, que sofre as consequências pela má administração, pela corrupção dos poderes públicos, pela ignorância da sociedade, sente-se cada vez mais revoltado, e a única coisa que pode pensar dentro daquele ambiente imundo, fétido, promíscuo, enfim, desumano, é em fugir e voltar a delinquir, já que a sociedade jamais o receberá com o fim de ajudá-lo (GRECO, 2014, p. 512-513).

Sustenta-se, por exemplo, inclusive entre nós, que a efetivação destes direitos fundamentais encontra-se na dependência da efetiva disponibilidade de recursos por parte do Estado, que, além disso, deve dispor do poder jurídico, isto é, da capacidade jurídica de dispor. Ressalta-se, outrossim, que constitui tarefa cometida precipuamente ao legislador ordinário a de decidir sobre a aplicação e destinação de recursos públicos, inclusive no que tange às prioridades na esfera das políticas públicas, com reflexos diretos na questão orçamentária, razão pela qual também se alega tratar-se de um problema eminentemente de competência.

Para os que defendem esse ponto de vista, a outorga ao Poder Judiciário da função de concretizar os direitos sociais mesmo à revelia do legislador, implicaria afronta ao princípio da separação dos poderes e, por conseguinte, ao postulado do Estado de Direito (SARLET, 2003, p. 286).

O Princípio da Legalidade impõe limites ao árbitro judicial, mas não impede que o Estado observa a reserva legal - crie tipos iníquos e comine sanções cruéis e degradantes. Por isso impõe-se a necessidade de limitar ou, se possível, eliminar o arbítrio do legislador (BITENCOURT, 2004).

Os altos índices de reincidência têm sido, historicamente, invocados como um dos fatores principais da comprovação de efetivo fracasso da pena privativa de liberdade, a despeito da presunção de que, durante a reclusão, os internos são submetidos a um tratamento ressocializador. As estatísticas de diferentes países, dos mais variados parâmetros políticos, econômicos e culturais, são pouco animadoras, e, embora os países latino-americanos não apresentem índices estatísticos confiáveis (quando não, inexistentes), é este um dos fatores que dificultam a realização de uma verdadeira política criminal. Apesar da deficiência dos dados estatísticos, é inquestionável que a delinquência não diminui em toda a América Latina e que o sistema penitenciário tradicional não consegue reabilitar ninguém, ao contrário, constitui uma realidade violenta e opressiva e serve apenas para reforçar os valores negativos do condenado (BITENCOURT, 2004).

A prevenção especial consiste na função assinalada à pena, visando evitar ou atenuar a probabilidade de reincidência demonstrada pelo autor em face do delito cometido. Trata-se, é bem de ver, de uma projeção racional e idealista posto que não se admite a imposição da pena como um instrumento puramente compensatório e assim esvaziado de conteúdo ético. O mal deve também significar a esperança de um bem haurido pelo condenado, não como prazer em cumprir a pena - o que seria um absurdo - mas como um antídoto para o futuro (DOTTI, 1998)

A prisão, em vez de conter a delinquência, tem lhe servido de estímulo, convertendo-se em um instrumento que oportuniza toda espécie de desumanidade. Não traz nenhum benefício ao apenado; ao contrário, possibilita toda a sorte de vícios e degradações. A literatura especializada é rica em exemplos dos efeitos criminógenos da prisão. Enfim, a maioria dos fatores que dominam a vida carcerária imprime a esta um caráter criminógeno, de sorte que, em qualquer prisão clássica, as condições materiais e humanas podem exercer efeitos nefastos à personalidade dos reclusos. Mas, apesar dessas condições altamente criminógenas das prisões clássicas, tem-se procurado, ao longo do tempo, atribuir ao condenado, exclusivamente, a culpa pela eventual reincidência, ignorando-se que é impossível alguém ingressar no sistema penitenciário e não sair de lá pior que entrou (BITENCOURT, 2004).

Infelizmente o que se observa é um descaso do poder público em relação ao sistema penitenciário. A questão é que todos os direitos dos presos estão lhes sendo retirados, e, o que se vê, são humanos tratados como animais. $\mathrm{O}$ verdadeiro intuito da instituição prisão, que é ressocializar os detentos para que quando saírem de lá possam levar uma vida o mais parecido com a normal possível, está 
sendo desconsiderado e dando lugar para uma realidade desumana que cria apenas revolta e raiva.

\section{REFERÊNCIAS}

ALBERGARIA, J. Manual de direito penitenciário. Rio de Janeiro: Aide, 1993.

ALEXANDRINO, M.; PAUlo, V. Direito administrativo descomplicado. 18. ed. São Paulo: Método, 2010.

ARAUJO, L. A. D.; NUNES JÚNIOR, V. S. Curso de direito constitucional. 9. ed. São Paulo: Saraiva, 2005.

BECCARIA, C. Dos delitos e das penas. Tradução Flório de Angelis. Bauru: EDIPRO, 1993. 120 p.

BERTONCINI, M. E. S. N.; MARCONDES, T. C. A. A dignidade da pessoa humana e os direitos humanos no sistema prisional brasileiro. Disponível em: $<$ http://www.publicadireito.com. br/artigos/?cod $=$ ec1093fe1626f $25 \mathrm{~b}>$. Acesso em: 25 nov. 2016.

BITENCOURT, C. R. Falência da pena de prisão: causas e alternativas. São Paulo: Revista dos Tribunais, 1993. $352 \mathrm{p}$.

BITENCOURT, C. R. Tratado de direito penal - parte geral. Vol. I. São Paulo: Saraiva, 2004.

BRASIL. Código Penal. Decreto-Lei $n^{\circ} 2.848$, de 7 de dezembro de 1940. São Paulo: Vade Mecum Saraiva, 2016.

BRASIL. Constituição da República Federativa do Brasil de 1988. São Paulo: Vade Mecum Saraiva, 2016.

CORDEIRO, G. C. A privatização do sistema penitenciário brasileiro. Rio de Janeiro: Freitas Bastos, 2006.

DIÓGENES JÚNIOR, J. E. N. Considerações gerais dos direitos fundamentais. Disponível em: $<$ http://www.ambitojuridico.com.br/site/?n link=revista_artigos_leitura\&artigo_id $=11769>$. Acesso em 10 nov. 2016.
DOTTI, R. A. Bases alternativas para o sistema de penas. 2. ed. São Paulo: Editora Revista dos Tribunais, 1998.

FERRY, L. Aprender a viver. Rio de Janeiro: Objetiva, 2007. 93 p.

GOMES, L. F.; MAZZUOLI, V. O. O Brasil e o sistema interamericano de proteção dos direitos humanos. Disponível em: <http://www.aidpbrasil. org.br/O\%20Brasil $\% 20 \mathrm{e} \% 20 \mathrm{o} \% 20$ Sistema $\% 20$ Interamericano $\% 20 \mathrm{de} \% 20$ Direitos $\% 20$ Humanos. pdf $>$. Acesso em 30 nov. 2016.

GRECO, R. Curso de direito penal. 16. ed. Rio de Janeiro: Impetus, 2014.

MUAKAD, I. B. Prisão albergue: reintegração social, substitutos penais, progressividade de regime, penas alternativas. São Paulo: Atlas, 1998.

OLIVEIRA, C. S. De condenado a recuperando: a convergência entre LEP e método APAC. 2008. 101 f. (Dissertação de Mestrado) - Programa de Pós-graduação em Estudos Comtemporâneos, Universidade do Estado de Minas Gerais, Fundação Educacional de Divinópolis, Divinópolis, 2008.

SARLET, I. W. A eficácia dos direitos fundamentais. 3. ed. rev. ampl. Porto Alegre: Livraria do Advogado, 2003.

SIQUEIRA JUNIOR, P. H. A dignidade da pessoa humana no contexto da pósmodernidade: o direito no século XXI é tolerância, bom senso e cidadania. In: MIRANDA, J.; SILVA, M. A. M. (Coords.). Tratado luso-brasileiro da dignidade da pessoa humana. São Paulo: Quartier Latin, 2009.

TAVARES, A. R. Curso de direito constitucional. 8. ed. rev. atual. São Paulo: Saraiva, 2010.

TUGENDHAT, E. Lições sobre ética. 4. ed. Tradução Róbson Ramos dos Reis. Petrópolis: Editora Vozes, 2000. 